\title{
Carbon-Friendly Travel Plan Construction Using an Evolutionary Algorithm
}

\author{
Neil Urquhart \\ Center for Emergent Computing \\ Napier University \\ 10 Colinton Rd \\ Edinburgh, Scotland \\ n.urquhart@napier.ac.uk
}

\begin{abstract}
This paper discusses the use of an evolutionary algorithm to design workplace travel plans, to promote of car sharing and reduce carbon emissions from single-occupancy motor vehicles.
\end{abstract}

\section{Categories and Subject Descriptors}

F2.2 [Nonnumerical Algorithms and Problems]: Routing and layout

\section{General Terms}

Algorithms

\section{Keywords}

Carbon-Trading, Routing

\section{INTRODUCTION AND MOTIVATION}

According to statistics from the United Kingdom Department for Transport each car in the UK travelled an average of 2740 miles per year for commuting purposes [DFT$2005]$ in the UK, with an average occupancy of 1.2 persons. Within this scenario many employers are choosing to create low carbon travel plans for their employees by facilitating car sharing.

\section{PROBLEM DESCRIPTION}

Ths paper considers the design of a car-sharing plan for Napier University, Edinburgh, which will place employees into groups of up to 4 individuals who will share a car when travelling to or from work. The individual living furthest away uses a car to pick up the other group members on their way to work. The system optimises with respect to three objectives; The first objective being to reduce overall distance travelled by employees. The second being to reduce the extra distance travelled due to deviating to pick up other members of the group en-route. This deviation should not be greater than that allowed by the deviation constraint specified by that employee (as a /

Copyright is held by the author/owner(s). GECCO'07, July 7-11, 2007, London, England, United Kingdom. ACM 978-1-59593-697-4/07/0007.

\begin{tabular}{|r|r|r|r|}
\hline & Craiglockhart & Sighthill & Merchiston \\
\hline \% Dist saved & 58 & 50 & 50 \\
\% of cars arriving & 30 & 30 & 30 \\
\% deviation violations & 0 & 0 & 0 \\
\% time slot violations & 0 & 0 & 1 \\
\hline
\end{tabular}

Table 1: A summary of results obtained in this investigation.

\section{THE PLANNING ALGORITHM}

The Evolutionary Algorithm used maintains a steady-state population of 25 individuals. Each individual represents a potential plan for placing employees into groups of size 1 to 4. A solution builder determines the pickup order for each group and evaluates the solution according to the criterion described in section 2. Recombination consists of creating a new individual by adding groups selected from each parent, all children have a randomised mutation applied to them.

\section{RESULTS AND CONCLUSIONS}

Three university campuses within South West Edinburgh were included in the trial. The campuses employed 404, 248 and 520 people respectively. The system was initially tested on each site, with each individual being allocated a random time slot in the range (1..4) and a random deviation value in the range (10-100\%). The deviation constraint was altered through values of $10,30,40$ and $70 \%$ for each user, the number of timeslots was also increased from 1 to 4 . Each run was repeated 10 times and the averaged results are shown in table 1. Total planned commuter mileage was reduced by $50 \%$, and only about $30 \%$ of employees actually have to park at work. In every case individuals desires for deviation distance were met and only in a few cases at the largest campus were some individuals not placed in groups compatible with their timeslot. Future work, involves allowing a wider range of user variables to be taken into account, the constraining nature of such variables and their potentially random nature should create a search space that may be successfully explore using the evolutionary algorithm.

\section{REFERENCES}

Transport Statistics Bulletin: National Travel Survey 2004. Department for Transport. Crown Copyright July 2005. 